\title{
Hip fracture unit: beyond orthogeriatrics
}

\author{
Carlo Rostagno $^{1} \cdot$ Alessandro Cartei $^{2} \cdot$ Roberto Civinini $^{3} \cdot$ Domenico Prisco $^{1}$
}

Received: 11 January 2018 / Accepted: 1 March 2018 / Published online: 6 March 2018

(c) SIMI 2018

Worldwide fragility fractures, and in particular hip fracture, represent a clinical and social emergency [1]. It has been estimated, due to progressive population ageing, that the incidence will increase by nearly $60 \%$ over the next 20 years. Most patients with hip fracture are aged $>85$ years, have two or more severe comorbidities, and about $50 \%$ suffer from moderate to severe functional impairment [2]. Surgery in these patients is associated with a 30-day mortality that approaches, and often exceeds 10\% [3]. One year mortality after surgery for hip fracture is near $30 \%$ in comparison to $6.3 \%$ expected 1 -year mortality in a healthy age-matched population at the time of the fracture [4]. A recent paper reports that in centenarians, the risk of death in the group of patients who sustain hip fracture HF significantly exceeds that of the control cohort, especially in the 3 months after surgery [5]. In addition, more than $60 \%$ of surviving patients do not recover full autonomy in basic daily life activities after hip fracture.

Orthogeriatrics pioneering work is due to Devas and colleagues in Great Britain [6]. In their model, patients are transferred to a geriatric unit after surgery. As Devas wrote: "The most important physical sign in geriatric orthopedics is to see the patient walk. The next most important is to see that the patient can undertake the ordinary activities of daily living. Hence all treatment must be aimed at the restoration of both as quickly as possible." In a recent paper published by New England Journal of Medicine [7] the author suggests, and we agree, "a multidisciplinary approach to that patient's perioperative care-...- - with a focus on return to function,

Carlo Rostagno

carlo.rostagno@unifi.it

1 Dipartimento Medicina Sperimentale e Clinica Università di Firenze, Viale Morgagni 85, 50134 Florence, Italy

2 SOD medicina interna e post-chirurgica AOU Careggi, Florence, Italy

3 SOD traumatologia ed Ortopedia AOU Careggi, Florence, Italy activities of daily living, and appropriate assessment and treatment of osteoporosis."

International health-care models for the approach to elderly patients with hip fracture may be suggested as follows: (a) Geriatric consultant service in the orthopedic ward. The patient is treated in the orthopedic ward until transferral to a rehabilitation center. The geriatric consultative service is on request. (b) Orthopedic ward and daily consultative service. Geriatrician consults are provided from admission to discharge. (c) Geriatric and rehabilitation ward and orthopedic consultant service. The patient is followed at the geriatric ward and the orthopedic surgeon is consultative. (d) Orthopedic ward and integrated care. This is the most sophisticated model where the orthopedic surgeon and the geriatrician manage the patient together from admission until discharge. The patient is in an orthopedic ward, and the geriatrician is integrated into the orthopedic team. A multi-professional group with nurses, social workers, physiotherapists, and others is formed, and standardized treatment paths are implemented.

Although no prospective, randomized trials have been conducted to compare different models of orthogeriatrics, consultant models do not show significant advantage in comparison to traditional orthopedic management. Comprehensive geriatric assessment and intervention on admission seem related to more beneficial results, and integrated care shows the lowest mean values regarding in-hospital mortality rate, the lowest length of stay and the lowest mean time to surgery [8]. This is the approach of most orthogeriatric units [9].

Improved long-term functional results have been reported in orthogeriatric models; however, early postoperative mortality had been only slightly affected [10]. In the study by Husko et al. [11], intensive geriatric rehabilitation within hospital was compared to standard care in local community hospitals. No differences in mortality at discharge (4\% in both groups) are found, although functional recovery is more frequent in patients treated intensively. Similar results are reported by Bielza-Galindo et al. [12]. In other studies, hospital mortality in patients with hip fracture has been reported 
between 3.7 and $7.3 \%$ [12, 13]. Atrial fibrillation, heart failure, diabetes, renal failure, dementia are independently related to a higher risk of early death [13-17]. Recently Stenqvist et al. [18] compared 993 patients followed by an orthogeriatric service with a control group of 989 patients treated before implementation of the service. In-hospital mortality decreases $(3.1 \%$ vs. $6.3 \%, p 0.009)$ after orthogeriatric service introduction. The geriatricians optimized patients for surgery and improved care preoperatively.

Thus although the effects on functional recovery may be significantly influenced by intensive rehabilitation programs, the main objective of orthogeriatric units, only a careful preoperative evaluation and postoperative treatment of comorbidities and complications may allow a limitation of hospital mortality.

Since 2011 in AOU Careggi, Florence, a tertiary teaching hospital treating about 700 cases of hip fracture/year, there is in function, a multidisciplinary hip fracture Unit led by an internal medicine specialist as part of a Project of Italian Health Ministry [RF-2010-2316600]. The Unit also includes anesthesiologists, geriatricians, orthopedics, nurses, physiotherapists, Health Care and Social Agency staff. The objective of the Unit is not only to favor early and, if possible, complete functional recovery, but also to decrease in-hospital mortality, often due to cardiovascular causes, and complication rates. Less than $5 \%$ of patients are treated conservatively.

The main difference from previous organization models is the availability of a rapid (within the first $12 \mathrm{~h}$ from admission) accurate internist/geriatrician clinical evaluation, including bed-side echocardiography when needed (near $50 \%$ of cases), and pre- and post-operative systematic troponin assay. This approach allows detection of severe clinical comorbidities, assessment of cardiovascular conditions and volemic status, and therefore, an accurate risk stratification. Severe aortic stenosis is found in $7 \%$ of patients, moderate to severe mitral regurgitation in $18 \%$, and moderate to severe pulmonary hypertension in $25 \%$. Moreover, about $4 \%$ of patients have evidence of ischemic preoperative myocardial damage [19], and another 5\% develop postoperative myocardial infarction.

Most of the decompensated clinical conditions at admission are stabilized by the medical team in order to schedule surgical intervention within the first $48 \mathrm{~h}$ from trauma. At present, more than $80 \%$ of patients undergo early surgery, while before use of the Hip Fracture Unit, patients treated within $48 \mathrm{~h}$ were $26 \%$. Moreover, almost $50 \%$ of patients not treated within $48 \mathrm{~h}$ were in anticoagulant treatment at the moment of trauma. Close collaboration with anesthesiologists allowed the choice of the proper anesthesiology strategy (general vs. spinal in high risk patients, e.g., severe aortic stenosis or ischemic left ventricular dysfunction), and the sharing of the need
Table 1 Mortality expressed as incidence rate estimate before and after introduction of hip fracture unit

\begin{tabular}{lll}
\hline & Incidence rate estimate/1000 & $95 \% \mathrm{CI}$ \\
\hline 2011 & 2.61 & $1.52-4.18$ \\
2013 & 2.00 & $0.99-3.57$ \\
2014 & 1.69 & $0.78-3.17$ \\
2015 & 1.84 & $0.87-3.38$ \\
2016 & $1.05^{*}$ & $0.37-2.34$ \\
\hline
\end{tabular}

*Versus 2011, $p=0.014$

for brief observation in intensive care unit immediately after surgery. In high risk patients, orthopedic surgeons identify a less invasive intervention, and decreased intraoperative blood losses. In the postoperative period, the adoption of the modified early warning score (MEWS), measured every $4 \mathrm{~h}$, allows recognition and treatment of early hemodynamic, respiratory and neurological deteriorations. We observed a progressive reduction in mortality from 3.8\% in 2011 to $1.44 \%$ in 2016. In Table 1 in-hospital mortality recorded as a rate (events per 1000 person-days) with hospital stay as exposure time is reported. Incidence rate estimate decreases from 2.61 events per 1000 persondays (95\% CI 1.52-4.18) before hip fracture unit to 1.05 events per 1000 person-days (95\% CI $0.37-2.34$ ) in 2016 $(p=0.014)$. A similar trend is observed at 30 days from surgery. One year mortality is less than $20 \%$. Average length of hospital stay in these 5 years decreased from 17 to 12 days.

Demographic and clinical characteristics of patients did not significantly change in the period under observation. In particular mean age, gender distribution, percentage of main comorbidities and severity of functional impairment before trauma did not significantly change over time.

In conclusion, increasing age and comorbidities frequently affect the outcome in patients undergoing orthopedic surgery after trauma. An integrated team may contribute, through a careful preoperative risk stratification and a postoperative therapeutic optimization, to decreasing the time from hospital admission to surgery, perioperative complications and mortality, length of hospitalization. Moreover, it allows an understanding of the cause of falling, and to personalize a proper rehabilitation pathway. The next step will be the evaluation of cost-effectiveness of the present model.

\section{Compliance with ethical standards}

Conflict of interest The authors declare that they have no conflict of interest.

Statement of human and animal rights The study is part of a project of Italian Health Ministry and Regione Toscana-RF-2010-2316600- and was approved by Ethical Committee of Regione Toscana. 
Informed consent All patients gave written informed consent to treatment and collection of clinical data for research purposes at admission.

\section{References}

1. Sanders KM, Nicholson GC, Ugoni AM et al (2000) Health burden of hip and other fractures in Australia beyond 2000. Projections based on the Geelong osteoporosis study. Med J Aust 170:467-470

2. Brauer CA, Coca-Perraillon M, Cutler DM et al (2009) Incidence and mortality of hip fractures in the United States. JAMA 302:157

3. Hung WW, Egol KA, Zuckerman JD, Siu AL (2012) Hip fracture management: tailoring care for the older patient. JAMA 307(20):2185-2194

4. Abrahamsen van Staa T, Ariely R, Olson M, Cooper C (2010) Excess mortality following hip fracture: a systematic epidemiological review. Osteoporos Int 20:1633-1650

5. Mazzola P, Rea F, Merlino L, Belleli G, Dubner L, Corrao G, Pasinetti GM, Annoni G (2016) Hip Fracture Surgery and Survival in Centenarians. J Gerontol 71:1514-1518. https://doi.org/10.1093/ gerona/glw016

6. Devas MB (1974) Geriatric orthopaedics. Br Med J. 1(5900):190-192

7. Bhandari M, Swiontkowski M (2017) Management of acute hip fracture. N Engl J Med 377:2053-2062

8. Ikpeze TC, Mohney S, Elfar JC (2017) Initial preoperative management of geriatric hip fractures. Geriatric Orthop Surg Rehabil 8:64-66

9. Kammerlander C, Roth T, Friedman SM, Suhm N, Luger TJ, Kammerlander-Knauer U, Krappinger D, Blauth M (2010) Orthogeriatric service-a literature review comparing different models. Osteoporos Int 21(Suppl 4):S637-646

10. Hawley S, Javad MK, Prieto-Alhambra D, Lippet J, Sheard S, Arden NK, Cooper C, Judge A, The Refresch study group (2016) Clinical effectiveness of orthogeriatric and fracture liaison service models of care for hip fracture patients: population-based longitudinal study. Age Ageing 45:236-242
11. Huusko TM, Karppi P, Avikainen V, Kautiainen H, Sulkava R (2000) Randomised, clinically controlled trial of intensive geriatric rehabilitation in patients with hip fracture: subgroup analysis of patients with dementia. BMJ 321(7269):1107-1111

12. Bielza Galindo R, Ortiz Espada A, Arias Muñana E et al (2012) Opening of an acute orthogeriatric unit in a general hospital. Rev Esp Geriatr Gerontol. https://doi.org/10.1016/j.regg.2012.03.002 (Epub ahead of print)

13. Harris I, Madan A, Naylor J, Chong S (2012) Mortality rates after surgery in New South Wales. ANZ J Surg. https://doi.org/10.111 1/j.1445-2197.2012.06319.x

14. Kristoffersen DT, Helgeland J, Clench-Aas J, Laake P, Veierød MB (2012) Comparing hospital mortality-how to count does matter for patients hospitalized for acute myocardial infarction (AMI), stroke and hip fracture. BMC Health Serv Res 12(1):364 (Epub ahead of print)

15. Cullen MW, Gullerud RE, Larson DR, Melton LJ, Huddleston JM (2011) Impact of heart failure on hip fracture outcomes: a population-based study. J Hosp Med. 6(9):507-512. https://doi. org/10.1002/jhm.918 (Epub 2011 Oct 31)

16. Adunsky A, Arad M, Koren-Morag N, Fleissig Y, Mizrahi EH (2012) Increased 1-year mortality rates among elderly hip fracture patients with atrial fibrillation. Aging Clin Exp Res 24(3):233-238

17. Huang YF, Shyu YI, Liang J, Chen MC, Cheng HS, Wu CC (2012) Diabetes and health outcomes among older Taiwanese with hip fracture. Rejuvenation Res. 15(5):476-482. https://doi. org/10.1089/rej.2011.1308

18. Stenqvist C, Madsen CM, Riis T, Jørgensen HL, Duus BR, Lauritzen JB, van der Mark S (2016) Orthogeriatric service reduces mortality in patients with hip fracture. Geriatr Orthop Surg Rehabil. 7(2):67-73. https://doi.org/10.1177/215145851562529 6 (Epub 2016 Mar 2)

19. Rostagno C, Cammilli A, Di Cristo A, Polidori GL, Ranalli C, Cartei A, Buzzi R, Prisco D (2016) Acute coronary syndromes with significant troponin increase in patients with hip fracture prior to surgical repair: differential diagnosis and clinical implications. Intern Emerg Med 11(2):219-224. https://doi.org/10.1007/ s11739-0151348-8 (Epub 2015 Nov 12) 